and has a most worderful provision for preventing the erosion of the banks and for adding to the dry land. It is a squat bushy tree, and round the stem, to an extent equal to the spread of its branches, it sends up thickets of straight shoots a foot or two high. These, when the tide is up or the water in flood, catch all the stray branches, leaves, grass, \&c., that may be floating about, and also promote silt. By this contrivance, therefore, not only are the banks protected from the distinctive action of water, but also raised and consolidated. Again, as regards Mr. Stoney's observation of calcareous masses in timber, which was brought to the notice of the Asiatic Society of Bengal in r870 as a fresh discovery, it seems strange that the learned body in question did not know that the existence of such concretions, so far from being very rare, is an occasional and well-known phenomenon. Thus, in the Madras Fournal of Literature and Science for April-September, 1858, page 142, Prof. Mayer gives a qualitative analysis of a concretion of the kind found in a teak log. It consisted chiefly of magnesia, with potash, lime, silica, and a trace of iron. The substance, he says, "Must be looked on as a mixture, and not a true chemical compound." Again, he observes, "as a whole the substance thus hardened is insoluble in cold, and but slightly so in water of higher temperature. At $\mathbf{2 1} 2^{\circ}$, however, there is sensible action after a time. In diluted hydrochloric acid solubility ensues, hastened by increased temperature. Solution is attended by slight effervescence, some carbonic acid being liberated." He then proceeds to give an explanation of the process by which such mineral matters may be taken up from the soil and deposited in the tree. So far as I know the occurrence of such concretions in India was first brought to notice by Lieut., now Col. Hawkes, of the Madras Army, in 1858. He had seen them only in teak logs, and remarked that they generally occur "in what carpenters call a shake in the wood, but with this exception the logs are perfectly sound, and no communication whatever with the external air has been observed."

Government Central Museum, Madras, May I3

\section{Remarkable Discovery of a Murder in Bermuda}

THE following account of a murder which was committed in Bermuda in the autumn of 1878 is taken from a letter written to Gen. Sir J. H. Lefroy, C.B., F.R.S., lately Governor of these islands, and author of the "Annals of Bermuda," by the Attorney-General of the islands, Mr. S. Brownlow Gray. The mode of discovery of the crime is so remarkable that I think it ought to be put on record, and Sir J. H. Lefroy has kindly permitted me to make extracts from the letter for that purpose. I believe no account of the circumstances of the case has as yet been published in Europe. There seems to be no likelihood as to mistake regarding the facts. The special occurrence could probably only happen in the tropics in warm water.

\section{H. N. Moseley}

"In the autumn of 1878 a man committed a terrible crime in Somerset, which was for some time involved in deep mystery. His wife, a handsome and decent mulatto woman, disappeared suddenly and entirely from sight, after going home from church on Sunday, October 20. Suspicion immediately fell upon the husband, a clever young fellow of about thirty, but no trace of the missing woman was left behind, and there seemed a strong probability that the crime would remain undetected. On Sunday, however, October 27 , a week after the woman had disappeared, some Somerville boatmen looking out towar.ls the sea, as is their custom, were struck by observing in the I.ong Bay Channel, the surface of which was ruffled by a slight breeze, a long streak of calm such as, to use their own illustration, a cask of oil usually diffuses around it when in the water. The feverish anxiety about the missing woman suggested some strange connection between this singular calm and the mode of her disappearance. Two or three days after-why not sooner I cannot tell you-her brother and three other men went out to the spot where it was observed, and from which it had not disappeared since Sunday, and with a series of fish-hooks ranged along a long line dragged the bottom of the channel, but at first without success. Shifting the position of the boat, they dragged a little further to windward, and presently the line was caught. With water glasses the men discovered that it had caught in a skeleton which was held down by some heavy weight. They pulled on the line ; something suddenly gave way, and up came the skeleton of the trunk, pelvis, and legs of a human body, from which almost every vestige of flesh had disappeared, but which, from the minute fragments remaining, and the terrible stench, had evidently not lain long in the water. The husband was a fisherman, and Long Bay Channel was a favourite fishingground, and he calculated, truly enough, that the fish would very soon destroy all means of identification; but it never entered into his head that as they did so their ravages, combined with the process of decomposition, would set free the matter which was to write the traces of his crime on the surface of the water. The case seems to be an exceedingly interesting one ; the calm is not mentioned in any book on medical jurisprudence that I have, and the doctors seem not to have had experience of such an occurrence. A diver went down and found a stone with a rope attached, by which the body had been held down, and also portions of the scalp and of the skin of the sole of the foot, and of clothing, by means of which the body was identified. The husband was found guilty and executed."

\section{On the Simplest Continuous Manifoldness of Two Dimensions and of Finite Extent}

THERE appeared in your pages some three years ago (vol. xv. p. 515) an article of mine "On the Simplest Continuous Manifoldness of Two Dimensions and of Finite Extent." In a succeeding number a correspondent (Mr. Monro, of Barnet) propounded a query which may be shortly stated as follows :"How does it happen that the perpendicular on a geodesic from a point moving along another geodesic changes sign without passing through either the value zero (o) or the value infinity $(\propto)$ ?" The problem here suggested is a peculiarly knotty one. In the case of the Euclidian plane the perpendicular of course changes sign by passing through the value $\propto$, while in the case of a spherical surface it is equally obvious that the perpendicular passes through zero, since the two geodesics intersect twice. But what are we to say of the strange hybrid surface which formed the subject-matter of my paper? Your correspondent appeared to insinuate that the problem was insoluble, and that the definition of the surface must therefore involve a logical contradiction. For a while I was greatly puzzled by this unforeseen difficulty, but after a little thought came to the conclusion that the perpendicular changes sign by passing through the value $\frac{l}{2} \sqrt{-1}$, where $l$ is positive and represents the absolute length of a complete geodesic. In other words, I conceived that the sign of the perpendicular changed from + to - by a continuous variation of the real numbers $a$ and $b$ in the complex number $a+b \sqrt{-1}$. I conceived $a$ to diminish continuously till, passing through 0 , it became $-a$, while $b$ at the same time increased with simple harmonic motion from 0 to a maximum, and then decreased from a maximum to 0 .

I was, however, not sufficiently clear on the matter to feel justified in addressing you until I received, the other day, a copy of a paper by Prof. Simon Newcomb, of the United States Observatory, entitled "Elementary Theorems relating to the Geometry of a Space of Three Dimensions and of Uniform Positive Curvature in the Fourth Dimension." 1 The subjectmatter of this masterly paper is in reality the simplest continuous manifoldness of three dimensions and of finite extent. It therefore naturally includes all that had been worked out in my own paper and a little more besides. In particular it throws strong light on the difficulty raised by your correspondent. For an exactly parallel anomaly presents itself in the theory of Prof. Newcomb's solid space, and is stated in his I $3^{\text {th }}$ Prcposition as follows:- "The two sides of a complete plane ${ }^{2}$ are not distinct, as in a Euclidian surface." If a being were to travel along a complete plane in a geodesic line, he would, on his return, find himself on the opposite side of the plane to that on which he started, and would have to repeat his journey in order to regain his original poise. "In this property," Prof. Newcomb says, "we find a certain amount of reason for considering the complete plane as a double surface." The corresponding anomaly in space of two dimensions-i.e., the specific feature noticed as an anomaly by your correspondent-is then explained as Propo. sition XIV.: "The following proposition is intimately connected with the preceding one. If, moving along a right line, we erect an indefinite series of perpendiculars, each in the same Euclidian plane with the one which precedes it, then, on completing the

I Abdruck aus dem Journal fïr die reine und angewandte Mathematil, Bd. 83. Druck von G. Reimer in Berlin.

surface of Prof. Newcomb's space. It is in all respects identical with the surface treated of in my paper. 